\title{
The Effects of Reservoir Parameters on Inflow Performance Relationship (IPR) of a Gas Field
}

\author{
Saeed S. Basaleh ${ }^{1}$, Salem O. Baarimah ${ }^{2}$, Ala AL-Dogail ${ }^{3}$ \\ Hadhramout University, Hadhramout-Yemen ${ }^{1,2}$ \\ Hadhramout University and King Fhed University of Petroleum and Minerals ${ }^{3}$
}

\begin{abstract}
The Inflow Performance Relationship (IPR) is considered one of the diagnostic tools used by petroleum engineers to evaluate the performance of a flowing well. An accurate prediction of well IPR is very important to determine the optimum production scheme, design production equipment, and artificial lift systems. For these reasons, there is a need for a quick and reliable method for predicting the well IPR in gas reservoirs. This study presents the effects of reservoir parameters on Inflow Performance Relationship (IPR) of a gas field. In order to achieve the IPR sensitivity analysis parameters, the skin factor, the gas permeability, the reservoir temperature, the reservoir thickness, nondarcy coefficient, the gas viscosity, and the compressibility factor were used to see the IPR sensitivity analysis. These models were developed using 2500 data sets collected from published literature papers and conventional PVT reports.
\end{abstract}

Keywords: Reservoir parameters, inflow performance relationship, gas field

\section{INTRODUCTION}

All well deliverability equations describe the relationship between the well production rate and the drawdown pressure, i.e. the difference between the reservoir pressure and the flowing bottom hole pressure. Presenting the production rate as a function of the drawdown pressure helps in comparing wells as well as in estimating the production rate under various conditions. This is also known as the inflow performance relationship (IPR).

In a single-layered gas reservoir, the gas well deliverability can be approximated using a pseudo-steady state relationship developed from Darcy's law as follows:

$$
m(\overline{\mathrm{P}})-\mathrm{m}(\mathrm{Pwf})=\frac{1424 q T}{k h}\left[\ln \left(\frac{0.472 r e}{r w}\right)+S+D q\right]
$$

Which can be rearranged as:

$$
m(\overline{\mathrm{P}})-\mathrm{m}(\mathrm{Pwf})=\frac{1424 q T}{k h}\left[\ln \left(\frac{0.472 r e}{r w}\right)+S\right] q+\frac{1424 T D}{k h} q^{2}
$$

Alternatively:

$$
m(\overline{\mathrm{P}})-\mathrm{m}(\mathrm{Pwf})=a q+b q^{2}
$$

Where:-

$$
\begin{array}{r}
a=\frac{1424 q T}{k h}\left[\ln \left(\frac{0.472 r e}{r w}\right)+S\right] \\
b=\frac{1424 T D}{k h} \ldots \ldots \ldots \ldots \ldots
\end{array}
$$

The $D q$ term refer to the turbulence skin effect, which could be quite high for some high rate wells. Several authors proposed approximations for the non-Darcy coefficient (D). One is the following empirical correlation:

$$
\begin{gathered}
D=\frac{2.715 \times 10^{-12} \beta M P s c}{h \mu g(P w f) r w T s c} \ldots \\
\beta=1.88 * 10^{10} K^{-1.47} \emptyset^{-0.53}
\end{gathered}
$$

It was found that much simpler equation evolving the pressure square rather than the pseudo-pressure could obtain almost the same results as follows: 


\section{International Advanced Research Journal in Science, Engineering and Technology}

Vol. 7, Issue 4, April 2020

$$
\overline{\mathrm{P}}^{2}-P_{w f}^{2}=\frac{1424 \bar{\mu} \overline{\mathrm{z}} T q}{k h}\left[\ln \left(0.472 \frac{r_{e}}{r_{w}}\right)+S+D q\right] \ldots
$$

Which can be rearranged as:

$$
\overline{\mathrm{P}}^{2}-P_{w f}^{2}=\frac{1424 \bar{\mu} \overline{\mathrm{z}} T}{k h}\left[\ln \left(0.472 \frac{r_{e}}{r_{w}}\right)+S\right] q+\frac{1424 \bar{\mu} \overline{\mathrm{z}} T D}{k h} q^{2}
$$

Alternatively:

$$
\overline{\mathrm{P}}^{2}-P_{w f}^{2}=a q+b q^{2}
$$

Where:

$$
\begin{array}{r}
a=\frac{1424 \bar{\mu} \overline{\mathrm{z} T}}{k h}\left[\ln \left(0.472 \frac{r_{e}}{r_{w}}\right)+S\right] . \\
b=\frac{1424 \bar{\mu} \overline{\mathrm{z}} T D}{k h} \ldots \ldots \ldots \ldots \ldots . . . . . . . . .
\end{array}
$$

In addition, the gas well deliverability can be approximated using pressure approach as follows:

$$
\overline{\mathrm{P}}-P_{w f}=\frac{141.2 * 10^{3} B_{g} \bar{\mu} q}{k h}\left[\ln \left(\frac{0.472 r_{e}}{r_{w}}\right)+S+D q\right]
$$

Which can be rearranged as:

$$
\overline{\mathrm{P}}-P_{w f}=\frac{141.2 * 10^{3} B_{g} \bar{\mu}}{k h}\left[\ln \left(\frac{0.472 r_{e}}{r_{w}}\right)+S\right] \mathrm{q}+\frac{141.2 * 10^{3} B_{g} \bar{\mu} D}{k h} q^{2} \ldots
$$

Alternatively:

$$
\overline{\mathrm{P}}-P_{w f}=a q+b q^{2}
$$

Where:

$$
\begin{gathered}
a=\frac{141.2 * 10^{3} B_{g} \bar{\mu}}{k h}\left[\ln \left(\frac{0.472 r_{e}}{r_{w}}\right)+S\right] \\
b=\frac{141.2 * 10^{3} B_{g} \bar{\mu} D}{k h} \ldots \ldots \ldots \ldots \ldots
\end{gathered}
$$

A good number of previous work has discussed the inflow performance relationship of a oil reservoirs. So far, only few publications are available in literature for the inflow performance relationship of a gas reservoirs

\section{Data Description}

A huge data sets used for this work were collected from conventional PVT reports for a Yemeni dry gas reservoir. Each data set contains gas flow rate, bottom hole flowing pressure, gas viscosity, gas compressibility factor. Statistical distributions such as maximum, minimum, mean, range, mid-range and standard deviation of the input data are shown in Table (1).

As can be seen from Table (1) gas flow rate of the data ranged between 12MSCF/D to $5528 \mathrm{MSCF} / \mathrm{D}$. For bottom hole flowing pressure, the data ranged between 15 psia to 5991 psia. Gas viscosity ranged from $0.009 \mathrm{cp} 0.035 \mathrm{cp}$. For gas compressibility factor, the data ranged between 0.745 to 0.999 . The average reservoir temperature is $180^{\circ} \mathrm{F}$. Reservoir permeability is $0.15 \mathrm{md}$, reservoir drainage radius and reservoir thickness are $1400 \mathrm{ft}$ and $80 \mathrm{ft}$, respectively.

\begin{tabular}{|c|c|c|c|c|c|c|}
\hline Property & Min & Max & Range & Mid-Ran. & Mean & Std \\
\hline$q$ & 12 & 5528 & 5516 & 2770 & 3325.747 & 1676.5 \\
\hline$p w f$ & 15 & 5991 & 5976 & 3003 & 3003.074 & 1729 \\
\hline$\mu_{g}$ & 0.009 & 0.035 & 0.026 & 0.022 & 0.0217 & 0.008 \\
\hline$Z$ & 0.745 & 0.999 & 0.255 & 0.872 & 0.8555 & 0.088 \\
\hline
\end{tabular}




\section{International Advanced Research Journal in Science, Engineering and Technology}

Vol. 7, Issue 4, April 2020

\section{RESULTS AND DISCUSSION}

Three skin factor cases were analysed (5, 0 and -5) to investigate the effect of skin factor on inflow performance relationship (IPR) of a gas field as shown in Fig. 1. As noted in this fig., there are apparent and significant effects of skin factor on inflow performance relationship (IPR) of a gas field. In order to study the effect of formation permeability on inflow performance relationship, three formation permeability of $0.1 \mathrm{md}, 0.15 \mathrm{md}$ and $0.2 \mathrm{md}$ were studied as presented in Fig. 2. From this figure, we can observe that there are minimal effect of gas formation permeability on inflow performance relationship.

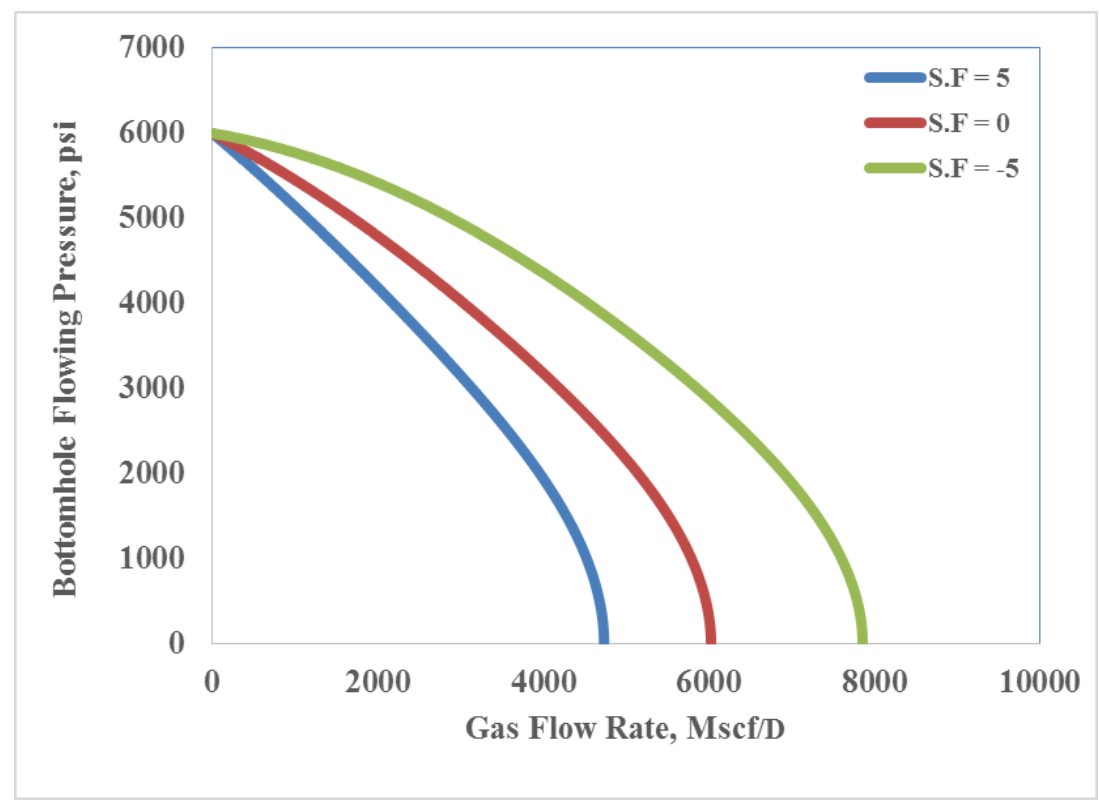

Figure 1 IPR sensitivity analysis of the skin factor

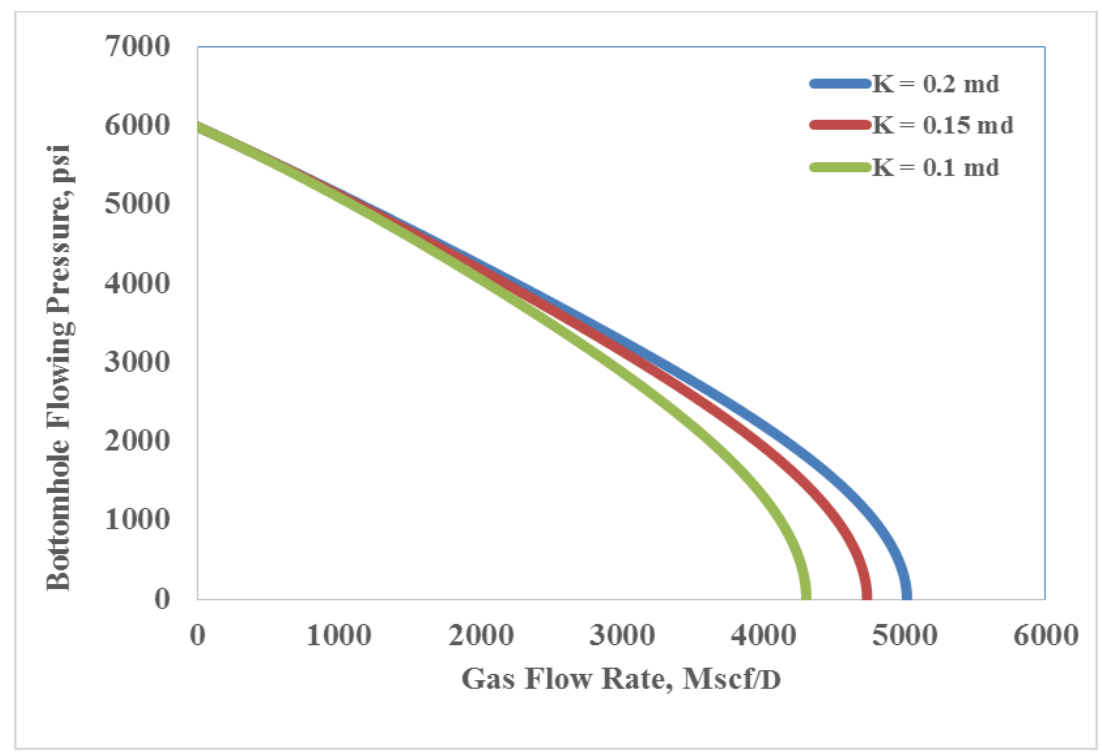

Figure 2 IPR sensitivity analysis of the gas permeability

For reservoir temperature, three reservoir temperature cases were analysed $\left(100{ }^{0} \mathrm{~F}, 180{ }^{0} \mathrm{~F}\right.$ and $\left.300{ }^{0} \mathrm{~F}\right)$ to consider the effect of reservoir temperature on inflow performance relationship (IPR) of a gas field as shown in Fig. 3. As noted in this fig., there are apparent and significant effects of reservoir temperature on inflow performance relationship (IPR) of a gas field. In order to study the effect of reservoir thickness on inflow performance relationship, three reservoir thickness of $50 \mathrm{ft}, 80 \mathrm{ft}$ and $110 \mathrm{ft}$ were investigated as presented in Fig. 4. From this figure, we can observe that there are insignificant effect of reservoir thickness on inflow performance relationship. 


\section{International Advanced Research Journal in Science, Engineering and Technology}

Vol. 7, Issue 4, April 2020

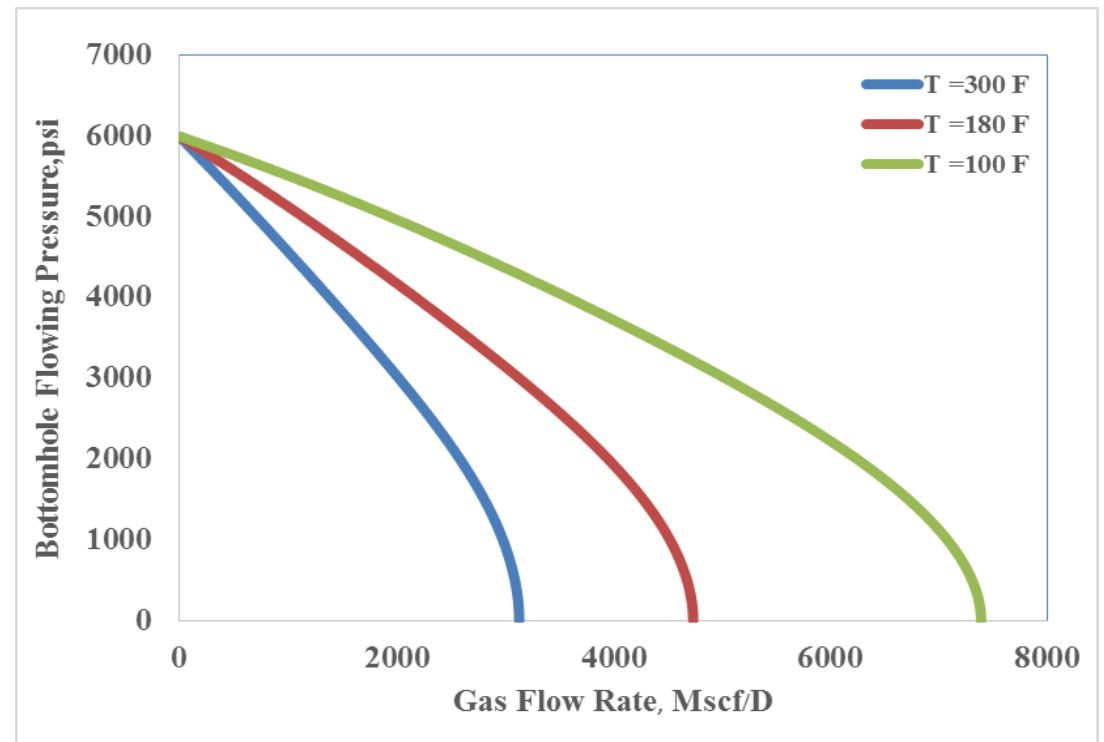

Figure 3 IPR sensitivity analysis of the reservoir temperature

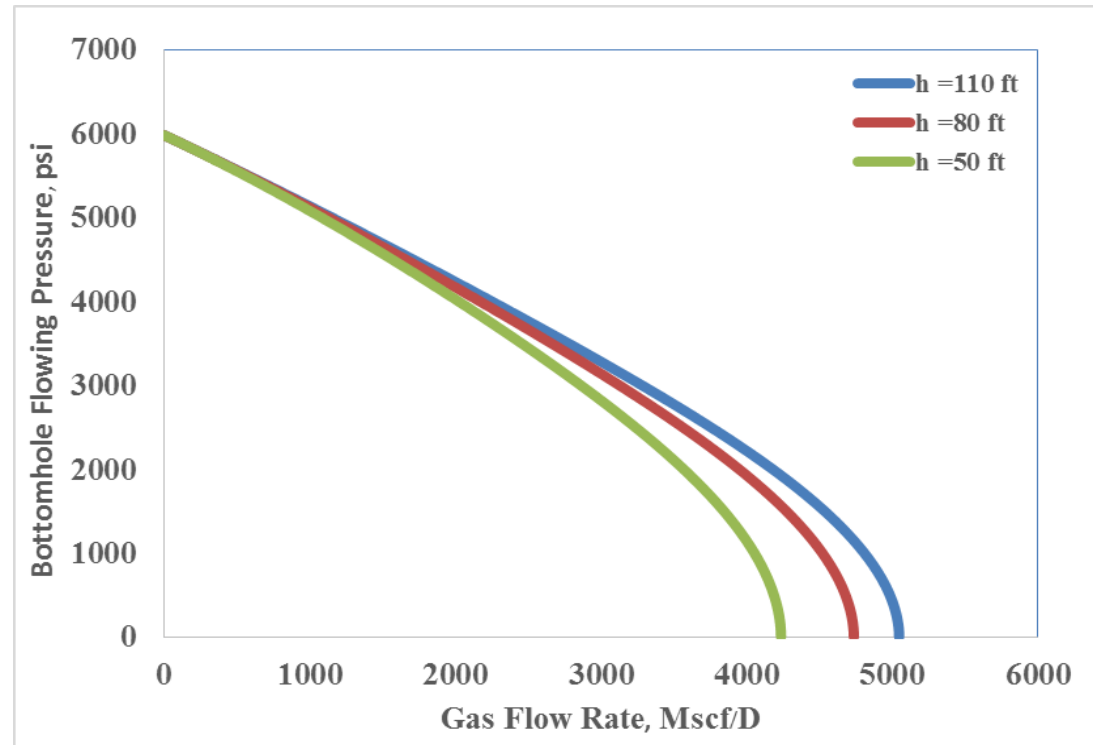

Figure 4 IPR sensitivity analysis of the reservoir thickness

For nondarcy coefficient ,three nondarcy coefficient cases were analysed $(0.005,0.001$ and 0.002$)$ to examine the effect of nondarcy coefficient on inflow performance relationship (IPR) of a gas field as shown in Fig. 5. As noted in this fig., there are apparent and significant effects of nondarcy coefficient on inflow performance relationship (IPR) of a gas field. Fig.6 shows the effect of gas viscosity on inflow performance relationship. As noted in this fig., three gas viscosity cases were investigated $(0.01 \mathrm{cp}, 0.1 \mathrm{cp}$ and $0.3 \mathrm{cp})$. In order to study the effect of compressibility factor on inflow performance relationship, three compressibility factor of $0.7,0.855 \mathrm{md}$ and 0.9 md were investigated as presented in Fig. 7. From this figure, we can observe that there are minimal effect of compressibility factor on inflow performance relationship. 
International Advanced Research Journal in Science, Engineering and Technology

Vol. 7, Issue 4, April 2020

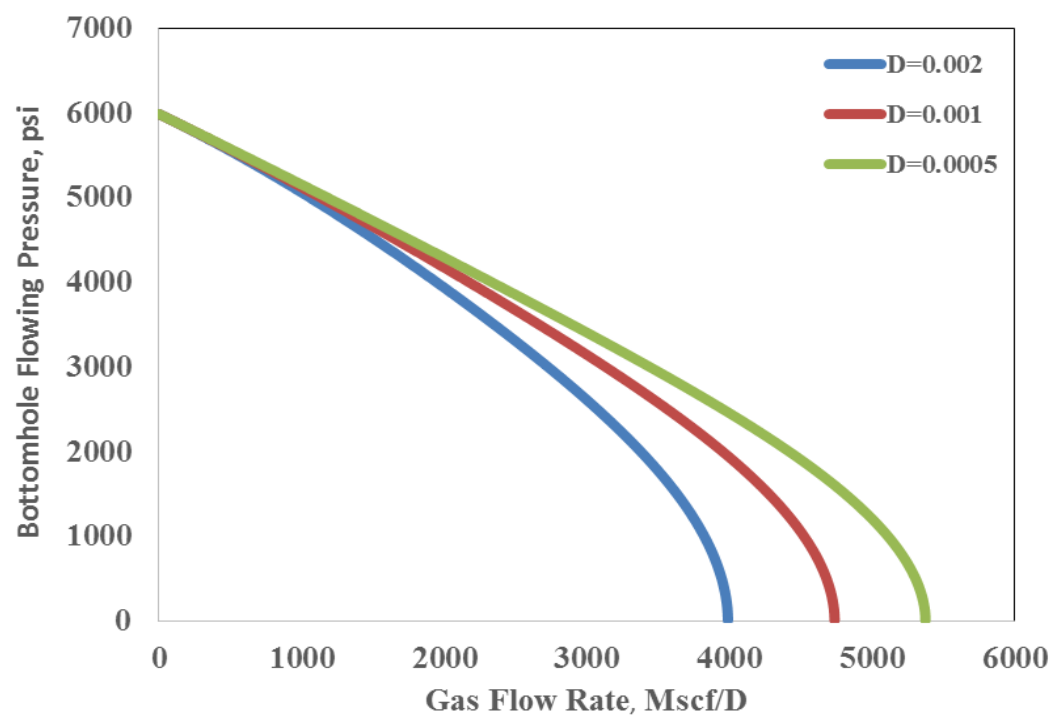

Figure 5 IPR sensitivity analysis of nondarcy coefficient

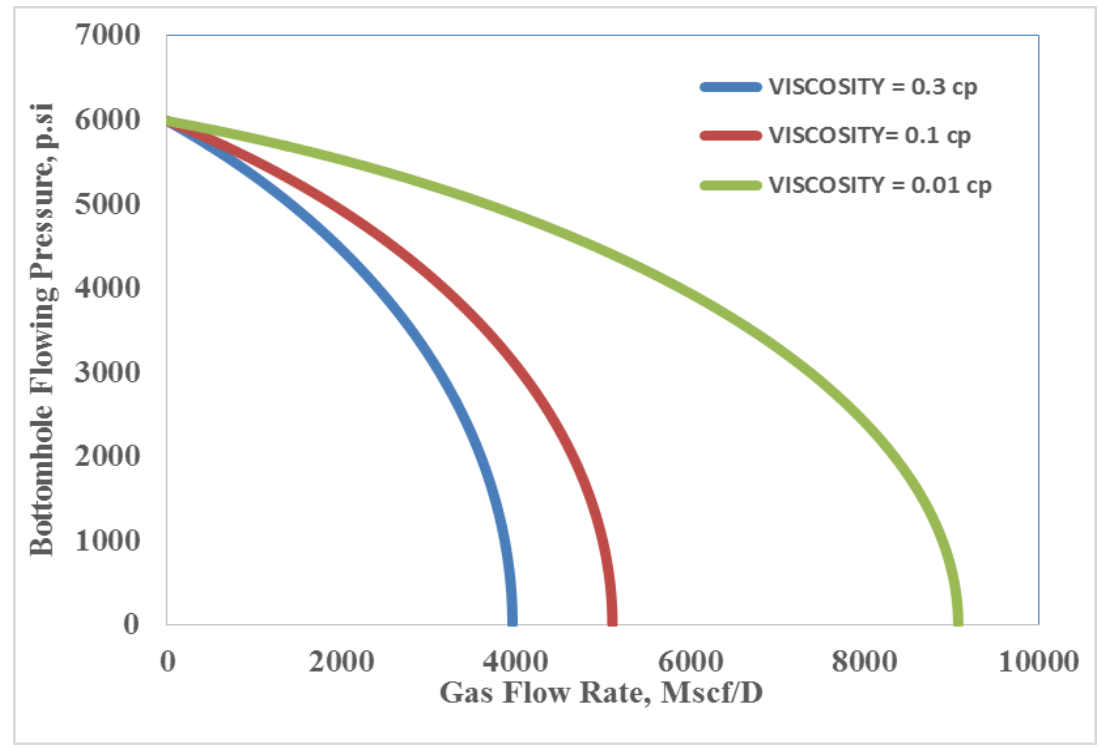

Figure 6 IPR sensitivity analysis of gas viscosity 


\section{International Advanced Research Journal in Science, Engineering and Technology}

Vol. 7, Issue 4, April 2020

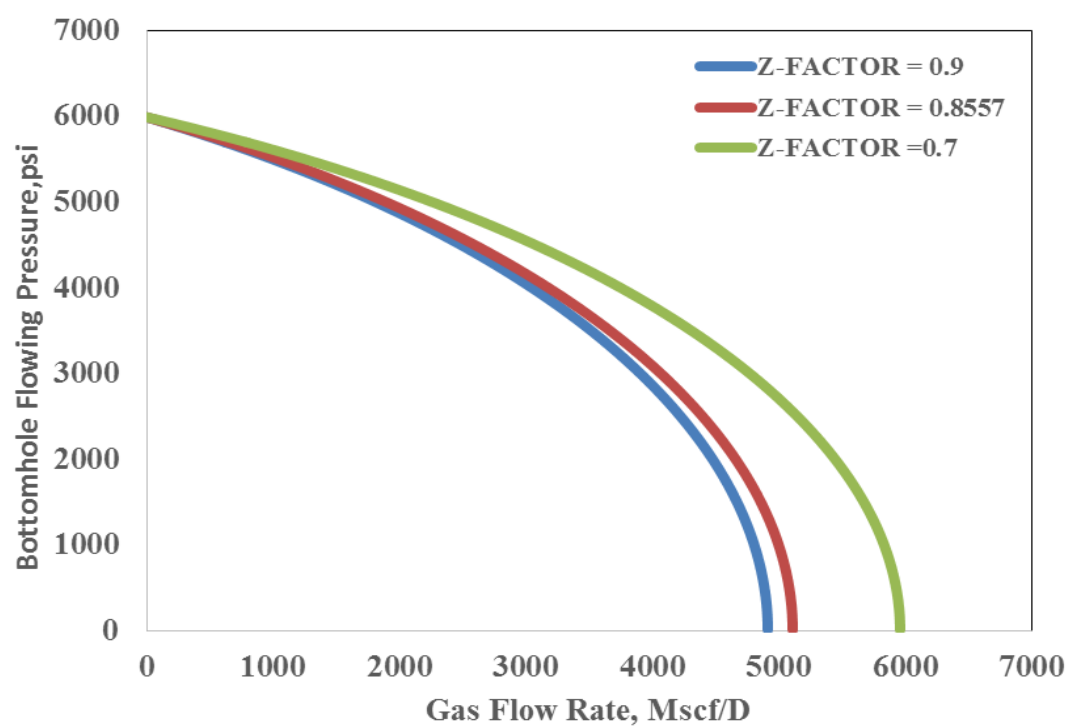

Figure 7 IPR sensitivity analysis of compressibility factor

\section{IV.CONCLUSION}

Based on the analysis of the results obtained in this research study, the following conclusions can be made:-

In this study, the skin factor, gas permeability, reservoir temperature, reservoir thickness, nondarcy coefficient, gas viscosity, and compressibility factor were used to see the inflow performance relationship (IPR) sensitivity analysis. There are apparent and significant effects of skin factor, reservoir temperature, nondarcy coefficient and gas viscosity on inflow performance relationship (IPR) of a gas field.

There are minimal effect of gas formation permeability, reservoir thickness and compressibility factor on inflow performance relationship.

\section{REFERENCES}

[1]. A. AL-dogail, S. O. Baarimah, S. Basfar, " Prediction of inflow performance relationship of a gas field using artificial intelligence techniques," Paper SPE 192273, presented at the SPE Kingdom of Saudi Arabia Annual Technical Symposium and Exhibition , Dammam, Saudi Arabia, 23-26 April 2018.

[2]. M.A. Klins, and M.W. Majher, "Inflow performance relationships for damaged or improved wells producing under solution-gas drive," Paper SPE 19852, JPT, p. 1357-1363, Dec. 1992.

[3]. M. L. Wiggins, "Generalized inflow performance relationship for three-phase flow" Paper SPE 25458, presented at Production Operations Symposium, Oklahoma City, OK, March 21-23, 1993.

[4]. M. L. Wiggins, J. L. Russel, and J. W. Jennings, "Analytical inflow performance relationships for three phase flow," Paper SPE 24055, presented at Western Regional Meeting, California, April 1992.

[5]. R. A. Archer, Y. D. Castillo, and T. A. Blasingame, "New perspectives on vogel type ipr models for gas condensate and solution-gas drive systems," Paper SPE 80907 presented at the SPE Production Operations Symposium, Oklahoma, OK, 23 -25 March, 2003.

[6]. Gallice, Frederic, and M. L. Wiggins, "A comparison of two-phase inflow performance relationships" Paper SPE 88445, the 1999 SPE MidContinent Operations Symposium, Oklahoma City, Oklahoma, March 28-31,1999.

[7]. S. Basfar, S. O. Baarimah, S. Elkatany, W. AL-Ameri, K. Zidan, and A, AL-dogail, "Using artificial intelligence to predict ipr for vertical oil well in solution gas derive reservoirs: a new approach," Paper SPE 192203, presented at the SPE Kingdom of Saudi Arabia Annual Technical Symposium and Exhibition, Dammam, Saudi Arabia, 23-26 April 2018

[8]. Z. Xiang, C.S. Kabir, " Simplified transient-IPR modeling in intermittent gas-lift and plunger-lift systems," Journal of Petroleum Science and Engineering, p. 31-43, 2019.

[9]. Z. Tariq, A. Abdulraheem, M. R. Khan, and A. Sadeed, "New inflow performance relationship for a horizontal well in a naturally fractured solution gas drive reservoirs using artificial intelligence technique," Paper OTC-28367-MS, presented at the Offshore Technology Conference Asia held in Kuala Lumpur, Malaysia, 20-23 March 2018.

[10]. A. A. Youssef, S. Alnuaim, “IPR of triple continuum reservoirs, analytical approach, Paper SPE-187973-MS, presented at the SPE Kingdom of Saudi Arabia Annual Technical Symposium and Exhibition held in Dammam, Saudi Arabia, 24-27April 2017.

[11]. A. Oyewole, M. Kelkar, E. Pereyra, and C. Sarica, “Well performance modeling in unconventional oil and gas wells, " Paper SPE-191694, presented at the 2018 SPE Annual Technical Conference and Exhibition held in Dallas, Texas, 24-26 September 2018.

[12]. C. Montoya, A. AlAdawy, and A. Malkawi, "Gas well performance analysis with downhole gas compression," Paper SPE-193310, presented at the Abu Dhabi International Petroleum Exhibition \& Conference held in Abu Dhabi, UAE, 12-15 November 2018.

[13]. T. Ahmed, and D. McKinney, Advanced reservoir engineering, Gulf Professional Publishing - Elsevier Inc., Oxford, UK (2005 